\title{
Factors favoring retrograde aortic dissection after endovascular aortic arch repair
}

\author{
Thomas Gandet, MD, Ludovic Canaud, MD, PhD, Baris Ata Ozdemir, MBBS, Vincent Ziza, MD, \\ Roland Demaria, MD, PhD, Bernard Albat, $\mathrm{MD}, \mathrm{PhD}$, and Pierre Alric, MD, $\mathrm{PhD}$
}

\section{ABSTRACT}

Objective: To assess factors predisposing patients to retrograde type A aortic dissection (RTAD) who have undergone hybrid aortic arch repair.

Methods: From 2001 to 2013, 32 patients underwent hybrid aortic arch repair in our department: 19 in zone 1 and 13 in zone 0 . Among these patients, 6 experienced RTAD (18.7\%): 3 in zone $0(23 \%), 3$ in zone $1(15.8 \%)$. Preoperative computed tomography scans of these 32 patients were evaluated. A morphologic assessment of the aortic arch, ascending aorta, and aortic root was performed. Other potential risk factors were investigated. Binary logistic regression was performed to test for possible associations with RTAD.

Results: Five patients were successfully converted to open repair. Patients who had RTAD were similar to those who did not, across pertinent variables, including age, type of device, diameter of the ascending aorta, and presence of a bicuspid aortic valve (all $P>.1$ ). Incidence of RTAD was observed to be higher among women $(P=.034)$, patients with stent-graft oversizing $\geq 10 \%(P=.018)$, and patients treated with a stent-graft of diameter $>42 \mathrm{~mm}(P=.01)$. Aortic morphology analysis showed that an indexed aortic diameter of $\geq 20 \mathrm{~mm} / \mathrm{m}^{2}$ $(P=.003)$; aortic root morphology, specifically loss of the sinotubular junction $(P=.004)$; and presence of an aortic arch malformation $(P=.03)$ were correlated with risk of RTAD. Two patients in the zone- 0 group with severe angulation $\left(>120^{\circ}\right)$ between the ascending and the transverse aorta suffered RTAD.

Conclusions: The occurrence of RTAD after hybrid aortic arch repair is common. To prevent this complication, preoperative screening of the aortic arch, ascending aorta, and aortic root morphology is critical. ( $\mathbf{J}$ Thorac Cardiovasc Surg 2015;150:136-42)

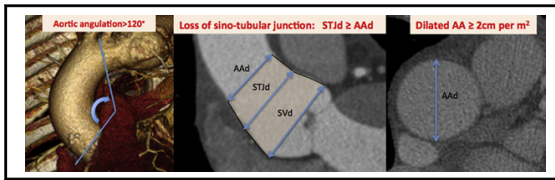

Aortic morphologic risk factors of retrograde dissection

\section{Central Message}

The occurrence of RTAD after hybrid aortic arch repair is common. To prevent this complication, preoperative screening of the aortic arch, ascending aorta, and aortic root morphology (indexed aortic diameter of $\geq 20 \mathrm{~mm} / \mathrm{m}^{2}$ and presence of aortic arch malformation) is critical.

\section{Perspective}

Thoracic endovascular aortic repair is increasingly being applied to treat aortic arch lesions. But this approach can induce retrograde aortic dissection. Of a total of 32 patients who underwent hybrid aortic arch repair, with landing in zone 1 or zone 0,6 experienced retrograde aortic dissection (18.7\%). A morphologic assessment of the 32 preoperative CT scans was conducted. Excessive stent-graft oversizing $(>10 \%)$, indexed aortic diameter of $\geq 20 \mathrm{~mm} / \mathrm{m}^{2}$, loss of sinotubular junction, aortic arch malformation, and being a woman were isolated as independent risk factors for retrograde dissection. Patients with such risk factors should either have open repair or hybrid aortic arch repair combined with prophylactic ascending aorta replacement.

See Editorial Commentary page 142.
From the Department of Thoracic and Cardio-Vascular Surgery, Arnaud de Villeneuve Hospital, Montpellier, France.

Received for publication Dec 6, 2014; revisions received March 22, 2015; accepted for publication March 29, 2015; available ahead of print May 1, 2015.

Address for reprints: Thomas Gandet, MD, Service de Chirurgie Thoracique et Cardio-vasculaire, Hôpital A de Villeneuve, 191 av Doyen Gaston Giraud 34090, Montpellier, France (E-mail: thomas.gandet@gmail.com).

0022-5223/\$36.00

Copyright (C) 2015 by The American Association for Thoracic Surgery http://dx.doi.org/10.1016/j.jtcvs.2015.03.042
Currently, management of aortic arch aneurysm remains a clinical challenge. Given the complexity of open arch procedures, hybrid strategies involving transposition of the great vessel and endovascular stent-grafting are increasingly applied to treat aortic arch aneurysm. ${ }^{1}$ Reductions in surgical trauma and procedural mortality and morbidity have been proposed as advantages of this novel technique. ${ }^{2}$ But thoracic endovascular repair (TEVAR) implantation landing proximally in "zones 0 and 1," in particular, is associated with severe 


\section{Abbreviations and Acronyms \\ $\mathrm{CI}=$ confidence interval \\ $\mathrm{CT}=$ computed tomography \\ RTAD = retrograde type A aortic dissection \\ TEE $=$ transesophageal echography \\ TEVAR $=$ thoracic endovascular repair}

complications, such as retrograde type A aortic dissection (RTAD). ${ }^{3-5}$ We report our institutional experience with a hybrid aortic arch operation, focusing particularly on predisposing factors of this devastating complication.

\section{METHODS}

From 2001 to May 2013, a total of 293 patients underwent TEVAR at our institution. Of these, 13 had TEVAR with a proximal aortic landing in "zone 0", and 19 in "zone 1," using the classification scheme proposed by Ishimaru. ${ }^{6}$ A total of 11 patients who had undergone prior ascending aortic replacement were excluded.

\section{Patient Demographics}

The mean age of patients was $69.8 \pm 8$ years; $27(84 \%)$ were men (demographics are shown in Table 1). Overall, $29(91 \%)$ patients had an American Society of Anesthesiologists score of $\geq 3 ; 12.5 \%$ of patients had had a prior stroke; $34 \%$ had had previous myocardial infarction; $19 \%$ had chronic lung disease; $22 \%$ had peripheral vascular disease; and $50 \%$ had some history of smoking. Of these, $29(91 \%)$ presented with aneurysmal disease of the aortic arch; 2 presented with chronic aortic dissection; and 1 presented with traumatic pseudoaneurysm. Three patients were treated after failure of prior TEVAR, and 16 patients $(50 \%)$ underwent emergency surgery for aortic rupture.

\section{Operative Strategy}

A total of 32 patients received hybrid aortic arch repairs with a suitable proximal landing zone. For zone-0 repair, surgical repair involved the reimplantation of the aortic arch vessel using a $10-\mathrm{mm}$ Dacron graft sewn to the native aorta just above the sinotubular junction. This procedure was performed without cardiopulmonary bypass, using a side-biting clamp. If exposure of the left subclavian was expected to be difficult through a median sternotomy, a pre-emptive transposition of the left subclavian to left common carotid artery was performed. After completion of the aortic arch debranching, a thoracic stent graft was deployed via a retrograde femoral approach during the same operative time. In 4 patients, stent-graft implantation was delayed until a later point during the same hospital stay. For zone 1, hemiarch debranching was performed by either a left carotid-subclavian transposition and carotid-to-carotid crossover bypass, or a sequential transposition of the left common carotid artery and of the left subclavian artery $^{7}$ (Figure 1).

During the same operative time, the stent-graft was deployed just distal to the brachiocephalic artery. Three thoracic stent-grafts were utilized: Gore Excluder (W.L. Gore \& Associates, Flagstaff, Ariz) $(\mathrm{n}=10$; $31.3 \%$ ); Gore TAG (W.L. Gore \& Associates) $(\mathrm{n}=7 ; 21.9 \%$ ); and Medtronic Talent (Medtronic, Inc, Santa Rosa, Calif) $(\mathrm{n}=15 ; 46.9 \%)$. Indications for each TEVAR were classified as degenerative aneurysm (including penetrating atherosclerotic ulcers) $(\mathrm{n}=29 ; 90.6 \%)$, acute and chronic dissection $(\mathrm{n}=2 ; 6.3 \%)$, or acute blunt traumatic aortic injury $(\mathrm{n}=1$; $3.1 \%$ ). Intraoperative transesophageal echography (TEE) was not routinely utilized.

\section{Follow-up}

All patients underwent a control computed tomography (CT) scan at 7 days, at 1 month, at 6 months, at 1 year, and annually thereafter. The mean follow-up period was 29.9 months (range: $1.25-171.8$ months).

\section{Morphologic Assessment}

Preoperative CT scans of these 32 patients were evaluated using OsiriX software (Mac app). A morphologic assessment of the aortic arch, the ascending aorta, and the aortic root was performed. Several measurements were made: ascending aortic diameter at 3 levels (ostium of the brachiocephalic trunk, half-length between the brachiocephalic trunk and the sinotubular junction, and sinotubular junction); sinus of Valsalva diameter; and the length between the aortic annulus and the origin point of the coronary arteries. Morphologic data were reported: bicuspid aortic valve; loss of sinotubular junction (an obliterated sinotubular junction was established when the sinotubular junction diameter was $\geq$ the ascending aorta diameter); malformation of the aortic arch (right-sided aortic arch, aberrant subclavian artery); and angulation between the ascending aorta and the transverse aorta (Figure 2).

\section{Statistical Analysis}

Statistical analysis was performed using SPSS (SPSS Inc, Chicago, Ill). Chi-square analysis, the Fisher exact test, and independent-sample $t$ tests were performed for the univariate analysis. Binary logistic regression was utilized to identify factors that were independently associated with each outcome of interest.

\section{RESULTS}

From 2001 to May 2013, a total of 32 consecutive TEVAR procedures were performed at a single institution, with a proximal landing in zone $0(\mathrm{n}=13)$ and zone 1 $(\mathrm{n}=19)$. Six patients experienced RTAD $(18.7 \%$, with $95 \%$ confidence interval $[\mathrm{CI}] 8.89 \%-35.31 \%)-3$ in zone $0(23 \%)$, and 3 in zone $1(15.8 \%)$.

\section{Operative Characteristics, Detection, and Management of RTAD}

Table 2 reports the clinical characteristics and management approach for the 6 RTAD cases. Patient 1 had RTAD originating adjacent to the origin of the inflow anastomosis of the bypass graft used for aortic arch debranching. Patient 2 suffered RTAD owing to an angiographic catheter tip abutting the carotid wall during a contrast injection; the dissection did not seem to be device related. Patients 3 and 4 both had a device-related dissection, based on findings at surgical repair (disclosing a tear adjacent to the proximal end of the endograft). With patient 5 , RTAD was disclosed by TEE: a large tear proximal to the stent-graft was observed. Owing to her comorbidities, the patient was deemed unsuitable for surgical conversion and died of multiorgan failure. Patient 6 had an RTAD originating from the anastomosis between the brachiocephalic trunk and the left common carotid artery.

All cases were identified after surgery (range: 3-7 days), but none was intraoperatively disclosed. Patients 2,3 , and 4 were asymptomatic, and the RTAD was found, thanks to the 
TABLE 1. Patient demographics

\begin{tabular}{lccc}
\hline Preoperative characteristics & All hybrid & Zone 0 & Zone 1 \\
\hline No. of patients & 32 & 13 & 19 \\
Age (y), mean & 69.8 & 73.5 & 68.8 \\
Gender, male & $27(84)$ & $11(85)$ & $16(84)$ \\
Emergency surgery & $16(50)$ & $7(54)$ & $9(47)$ \\
ASA score $\geq 3$ & $29(91)$ & $13(100)$ & $16(84)$ \\
Prior cerebrovascular accident & $4(12.5)$ & $2(15)$ & $2(10.5)$ \\
Chronic lung disease & $6(19)$ & $2(15)$ & $4(21)$ \\
Prior myocardial infarction & $11(34)$ & $6(46)$ & $5(26)$ \\
Chronic renal insufficiency & $4(12.5)$ & $1(8)$ & $3(16)$ \\
Peripheral arterial disease & $7(22)$ & $3(23)$ & $4(21)$ \\
Smoker & $16(50)$ & $7(54)$ & $9(47)$ \\
Aortic pathology & & & \\
Aneurysm & $29(91)$ & $13(100)$ & $16(84)$ \\
Chronic dissection & $2(6)$ & 0 & $2(10.5)$ \\
Aortic arch malformation & $2(6)$ & $1(8)$ & $1(5)$ \\
Failure of prior TEVAR & $3(9)$ & 0 & $3(16)$ \\
Posttraumatic transection & $1(3)$ & 0 & $1(5)$ \\
Redo sternotomy & $2(6)$ & $1(8)$ & $1(5)$ \\
Prior AAA & $7(22)$ & $5(38)$ & $2(10.5)$ \\
\hline
\end{tabular}

Values are $\mathrm{n}(\%)$, unless otherwise indicated. ASA, American Society of Anesthesiologists; TEVAR, thoracic endovascular repair; AAA, abdominal aortic aneurysm.

systematic postoperative CT scan. New-onset chest pain on day 6 after surgery prompted a CT scan for a definite diagnosis in patient 1 . For patient 5 , hemodynamic instability on the third day after surgery prompted TEE, which disclosed the presence of an RTAD. Patient 6 was discharged home on the 6th day after surgery. The control CT scan showed no anomalies. On the 7th day after surgery, an emergency CT scan for a stroke revealed an acute RTAD. Five of the 6 patients were treated with emergency open repair and were discharged home. Patient 5 had contraindications to surgery and died subsequently. Overall mortality was $16.6 \%$.



FIGURE 1. A postoperative CT scan shows (A) total arch debranching (zone 0 ) and (B) hemiarch debranching (zone 1).

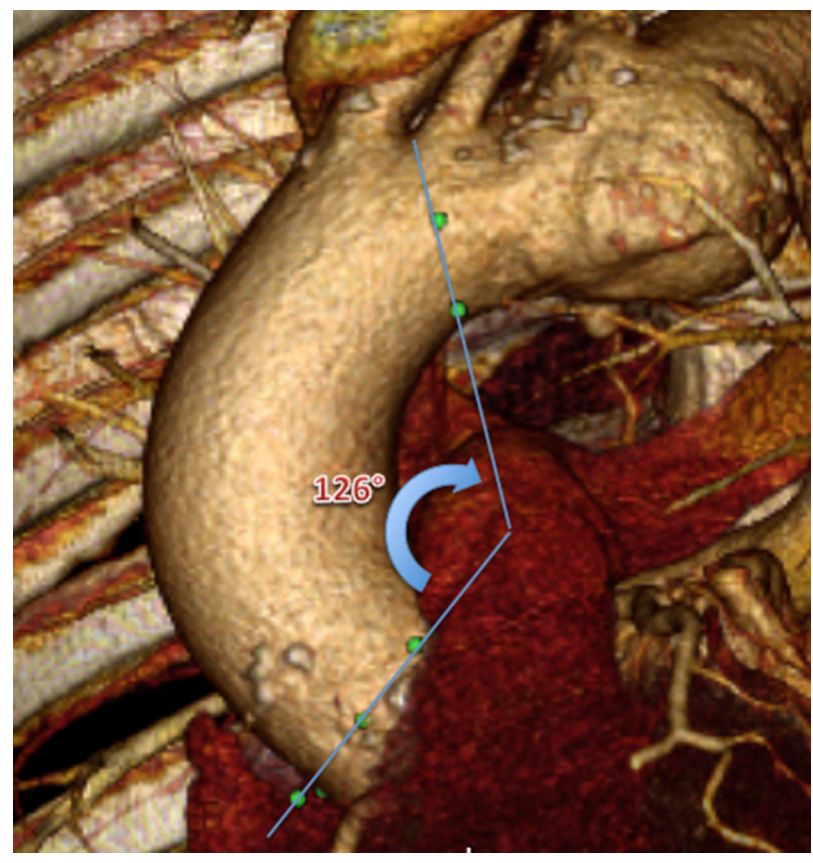

FIGURE 2. The image shows the aortic angulation between the ascending aorta (sinotubular junction) and the transverse aorta (between the brachiocephalic trunk and the left common carotid artery).

\section{Incidence of RTAD by Patient Characteristics, Indication, Aortic Morphology (Arch, Ascending Aorta, Root), and Device Used}

Table 3 describes patients, indication, aortic morphology, and operative variables stratified by whether patients had RTAD after TEVAR. Gender was correlated with RTAD, with significantly more women having RTAD $(8 \%$ vs $50 \%$, respectively; $P=.034$ ). Indications of TEVAR, and symptomatic presentation at the time of treatment, were not correlated with RTAD.

Aortic arch malformations (right-sided aortic arch, aberrant subclavian artery) were observed in $3.1 \%$ of all patients ( 2 of 32 ), representing 33\% (2 of 6 ) of RTAD cases $(P=.03)$. More patients who experienced RTAD had an ascending aortic diameter $\geq 40 \mathrm{~mm}(15 \%$ vs $33 \% ; P=.31$ ), but this difference was not statistically significant. Six of 15 patients $(43 \%)$ with ascending aortic diameter indexed to body surface area $\geq 20 \mathrm{~mm} / \mathrm{m}^{2}$ will develop RTAD, versus 0 of 18 patient with indexed aortic diameter $<20 \mathrm{~mm} / \mathrm{m}^{2}(P=.003)$. Aortic root diameter $(P=.31)$, a high origin of the right coronary artery $(P=.66)$, and presence of a bicuspid valve $(P=.66)$ were not correlated with the risk of RTAD. But morphology of the aortic root, especially the loss of the sinotubular junction, was associated with the risk of RTAD $(P=.004)$ (Figure 3).

A stent-graft with a proximal bare-stent accounted for $46 \%$ of patients in the non-RTAD group, and $50 \%$ of patients (3 of 6$)$ in the RTAD group $(P=1)$. A stent-graft 
TABLE 2. Operative characteristics, detection, and management of retrograde type A aortic dissection

\begin{tabular}{|c|c|c|c|c|c|c|}
\hline Characteristic & Patient 1 & Patient 2 & Patient 3 & Patient 4 & Patient 5 & Patient 6 \\
\hline Age (y) & 76 & 60 & 59 & 62 & 85 & 69 \\
\hline Gender & $\mathrm{F}$ & $\mathrm{F}$ & M & M & $\mathrm{F}$ & M \\
\hline Indication & Aneurysm & Aneurysm & Aneurysm & Type B dissection & Aneurysm & Aneurysm \\
\hline Diameter (mm) & 40 & 34 & 42 & 42 & 42 & 45 \\
\hline PLZ & 0 & 1 & 0 & 1 & 0 & 1 \\
\hline AA diameter (mm) & 36 & 34 & 36 & 44 & 35 & 42 \\
\hline SV diameter $(\mathrm{mm})$ & 32 & 34 & 38 & 47 & 30 & 44 \\
\hline \multicolumn{7}{|l|}{$\begin{array}{l}\text { Location of the tear, } \\
\text { by means of detection }\end{array}$} \\
\hline CT scan & $\begin{array}{l}\text { 10-mm graft } \\
\text { anastomosis }\end{array}$ & LCCA & $\begin{array}{l}\text { Tip of the } \\
\text { endograft }\end{array}$ & $\begin{array}{l}\text { Tip of the } \\
\text { endograft }\end{array}$ & - & $\mathrm{BCT}$ \\
\hline Surgery & $\begin{array}{l}\text { 10-mm graft } \\
\text { anastomosis }\end{array}$ & Not visible & $\begin{array}{l}\text { Tip of the } \\
\text { endograft }\end{array}$ & $\begin{array}{l}\text { Tip of the } \\
\text { endograft }\end{array}$ & - & Not visible \\
\hline TEE & - & - & - & - & AA & - \\
\hline Presumed etiology & Aortic side clamping & $\begin{array}{l}\text { Carotid } \\
\text { arteriography }\end{array}$ & Device related & Device related & $\begin{array}{l}\text { Device } \\
\text { suspected }\end{array}$ & $\begin{array}{l}\text { Carotid } \\
\text { transposition }\end{array}$ \\
\hline Time of diagnosis (POD) & 6 & 6 & 7 & 3 & 3 & 7 \\
\hline Symptoms & Chest pain & None & None & None & Instability & Stroke \\
\hline Treatment & Open surgery & Open surgery & Open surgery & Open surgery & None & Open surgery \\
\hline Outcomes & Uneventful & Uneventful & Uneventful & Uneventful & Death & Stroke alive \\
\hline
\end{tabular}

$F$, Female; $M$, male; $P L Z$, proximal landing zone; $A A$, ascending aorta; $S V$, sinus of Valsalva; $C T$, computed tomography; $L C C A$, left common carotid artery; $B C T$, brachiocephalic trunk; TEE, transesophageal echography; $P O D$, postoperative day.

with diameter $>42 \mathrm{~mm}$ was used in $15 \%$ of patient in the non-RTAD group, versus in $67 \%$ (4 of 6 ) in the RTAD group $(P=.023)$. In addition, stent-graft oversizing of $>20 \%$ was linked to the risk of RTAD: excessive oversizing was performed in $8 \%$ of patients in the non-RTAD group, versus $50 \%$ in the RTAD group $(P=.034)$. Similarly, oversizing of $\geq 10 \%$ was identified as a risk factor $(P=.018)$. The proximal landing zone was zone 0 for $38 \%$ of patients in the non-RTAD group, and for $50 \%$ in the RTAD group $(P=.66)$. In the zone-0 subgroup, aortic angulation between the ascending aorta and the transverse aorta of $>120^{\circ}$ was observed in $66 \%$ of the patients in the RTAD group ( 2 of 3 ); the angulation was always $<120^{\circ}$ in the non-RTAD group (Figure 3).

\section{DISCUSSION}

In our institution, between 2001 and 2013, hybrid aortic arch repair without cardiopulmonary bypass became the first-line therapy for high-risk patients with aortic arch diseases, especially for aortic arch aneurysm. ${ }^{2}$ All patients were considered to be at high surgical risk, owing to serious comorbidities (American Society of Anesthesiologists score of $\geq 3$ ) or because they were treated in an emergency setting.

Among 32 patients, we identified 6 cases of RTAD, for an overall incidence of $18.7 \%$. A recent systematic review ${ }^{3}$ reported 73 RTAD cases that followed 3211 TEVAR cases (incidence: $2.27 \%$ ). The incidence increases up to $6.8 \%$ after TEVAR with a proximal landing in zone 0 .

\section{Time of Diagnosis}

Many possible causative mechanisms for intimal tear that occurs intraoperatively or after surgery have been proposed. In this study, all cases of RTAD were identified during the perioperative course (range: 3 to 7 days). This timing can be explained by the absence of systematic TEE during the procedure. Three of 6 patients with RTAD were asymptomatic; the RTAD was disclosed during the systematic CT scan after surgery. We can speculate that these dissections are procedure related. In contrast to the MOTHER (Medtronic Thoracic Endovascular Registry) database, ${ }^{8}$ which showed that $50 \%$ of RTAD occurs after the 30th day after surgery, we did not identify any cases during the follow-up period. The potential factors that predispose patients to RTAD after TEVAR may be classified as procedure related, device related, and aorta related (from aortic wall fragility and aortic morphology).

\section{Procedure-Related RTAD}

The high rate of RTAD after TEVAR in zone 0 could be explained by the fact that the complexity of the reconstruction has increased. Three causative mechanisms of intimal tear during the procedure occurred in this study: aortic side-clamping under pulsatile flow, anastomosis between supra aortic trunk themselves, and damage to the arterial wall by catheter angiography. Wire manipulation, especially contact between stiff wire and the sinus of Valsalva during TEVAR with landing zone 0 , could induce an intimal trauma. 
TABLE 3. Incidence of RTAD by patient characteristics, indication, aortic morphology (arch, ascending aorta, root), and device used; operative variables were stratified by whether patients had RTAD after TEVAR

\begin{tabular}{|c|c|c|c|}
\hline Characteristics & Non-RTAD & RTAD & $P$ value \\
\hline No. of patients & 26 & 6 & \\
\hline Age $(y)$, mean \pm SD & $70.2 \pm 3$ & $68.2 \pm 4$ & .71 \\
\hline Gender & & & .034 \\
\hline Male & $24(89)$ & $3(11)$ & \\
\hline Female & $2(40)$ & $3(60)$ & \\
\hline Blood pressure & & & .55 \\
\hline Hypertensive & $21(78)$ & $6(22)$ & \\
\hline Normotensive & $5(100)$ & 0 & \\
\hline \multicolumn{4}{|l|}{ Aortic pathology: indication } \\
\hline Aneurysm & $24(83)$ & $5(17)$ & .66 \\
\hline Nonaneurysm & $2(67)$ & $1(33)$ & \\
\hline Type B dissection & $1(50)$ & $1(50)$ & .34 \\
\hline Non-type B dissection & $25(83)$ & $5(17)$ & \\
\hline Traumatic aortic injury & $1(4)$ & 0 & .66 \\
\hline Symptomatic & $12(75)$ & $4(25)$ & .65 \\
\hline Asymptomatic & $14(88)$ & $2(12)$ & \\
\hline \multicolumn{4}{|l|}{ Aortic morphology } \\
\hline Aortic diameter $1(\mathrm{BCT}) \geq 40 \mathrm{~mm}$ & $3(75)$ & $1(25)$ & $>.99$ \\
\hline Aortic diameter $1(\mathrm{BCT}) \leq 40 \mathrm{~mm}$ & $23(82)$ & $5(18)$ & \\
\hline Aortic diameter $2 \geq 40 \mathrm{~mm}$ & $4(67)$ & $2(33)$ & .31 \\
\hline Aortic diameter $2 \leq 40 \mathrm{~mm}$ & $22(85)$ & $4(15)$ & \\
\hline $\begin{array}{l}\text { Indexed aortic diameter } \\
2 / \mathrm{BSA} \geq 20 \mathrm{~mm} / \mathrm{m}^{2}\end{array}$ & $8(57)$ & $6(43)$ & .003 \\
\hline $\begin{array}{l}\text { Indexed aortic diameter } \\
2 / \mathrm{BSA} \leq 20 \mathrm{~mm} / \mathrm{m}^{2}\end{array}$ & $18(100)$ & 0 & \\
\hline Sinus of Valsalva diameter $\geq 40 \mathrm{~mm}$ & $4(67)$ & $2(33)$ & .31 \\
\hline Sinus of Valsalva diameter $\leq 40 \mathrm{~mm}$ & $22(85)$ & $4(15)$ & \\
\hline $\begin{array}{l}\text { Indexed sinus of Valsalva } \\
\text { diameter/BSA } \geq 20 \mathrm{~mm} / \mathrm{m}^{2}\end{array}$ & $10(71)$ & $4(29)$ & .36 \\
\hline $\begin{array}{l}\text { Indexed sinus of Valsalva } \\
\text { diameter/BSA } \leq 20 \mathrm{~mm} / \mathrm{m}^{2}\end{array}$ & $16(89)$ & $2(11)$ & \\
\hline Loss of sinotubular junction & 0 & $3(100)$ & .004 \\
\hline Normal sinotubular junction & $26(90)$ & $3(10)$ & \\
\hline $\begin{array}{l}\text { High origin of the right coronary } \\
\text { artery } \geq 15 \mathrm{~mm}\end{array}$ & $16(84)$ & $3(16)$ & .66 \\
\hline $\begin{array}{l}\text { High origin of the right coronary } \\
\text { artery } \leq 15 \mathrm{~mm}\end{array}$ & $10(77)$ & $3(23)$ & \\
\hline Aortic arch malformation & 0 & $2(100)$ & .03 \\
\hline Normal aortic arch morphology & $26(87)$ & $4(13)$ & \\
\hline Aortic bicuspid valve & $3(75)$ & $1(25)$ & $>.99$ \\
\hline Aortic trileaflet valve & $23(79)$ & $6(21)$ & \\
\hline \multicolumn{4}{|l|}{ Endograft } \\
\hline Landing in zone 0 & $10(77)$ & $3(23)$ & .66 \\
\hline Landing in zone 1 & $16(84)$ & $3(16)$ & \\
\hline Endograft diameter $\geq 42 \mathrm{~mm}$ & $4(50)$ & $4(50)$ & .023 \\
\hline Endograft diameter $\leq 42 \mathrm{~mm}$ & $22(92)$ & $2(8)$ & \\
\hline Oversizing $\geq 20 \%$ & $2(40)$ & $3(60)$ & .034 \\
\hline Oversizing $\leq 20 \%$ & $24(89)$ & $3(11)$ & \\
\hline Oversizing $\geq 10 \%$ & $10(62)$ & $6(38)$ & .018 \\
\hline Oversizing $\leq 10 \%$ & $16(100)$ & 0 & \\
\hline Proximal bare metal stent & $12(80)$ & $3(20)$ & $>.99$ \\
\hline Proximal covered stent & $14(82)$ & $3(18)$ & \\
\hline
\end{tabular}

TABLE 3. Continued

\begin{tabular}{lccc}
\hline Characteristics & Non-RTAD & RTAD & $\boldsymbol{P}$ value \\
\hline Type 1 proximal endoleak & $4(80)$ & $1(20)$ & $>.99$ \\
No type 1 proximal endoleak & $22(81)$ & $5(19)$ & \\
\hline Values are $\mathrm{n}(\%)$, unless otherwise indicated. Aortic diameter 1 is of the ostium of the \\
BCT. Aortic diameter 2 is the half-length between the BCT and the sinotubular \\
junction. $R T A D$, Retrograde type A aortic dissection; $S D$, standard deviation; $B C T$, \\
brachiocephalic trunk; $B S A$, body surface area.
\end{tabular}

\section{Device-Related RTAD}

Three of 6 RTAD cases were device related. Acute and dynamic interactions between the endograft and the native aorta probably played a central role. Van Prehn and colleagues ${ }^{9}$ have reported that the ascending aorta is quite compliant, in contrast to the rigidity of the stent-graft. This difference may explain the higher incidence of RTAD in zone 0. Additionally, an excessive radial force on the stent-graft has been proposed by Kpodonu and colleagues ${ }^{10}$ as a potential causative factor for RTAD after TEVAR.

In this study, oversizing of $>20 \%$ seemed to be related to RTAD. Excessive oversizing occurred in $8 \%$ of patients in the non-RTAD group, in contrast to $50 \%$ in the RTAD group $(P=.034)$. Canaud and colleagues ${ }^{3}$ demonstrated that graft oversizing $>9 \%$ seemed to translate to an increased relative risk of RTAD, by a factor of 1.4 for each additional percentage point of oversizing.

In the current study, for the subgroup with landing zone 0 , the aortic angulation between the ascending aorta and transverse aorta seems to be associated with retrograde dissection. Proximal aortic arch angulation of $>120^{\circ}$ occurred with $66 \%$ of patients in the RTAD group ( 2 of 3 ); the angulation was always $<120^{\circ}$ in the non-RTAD group (Figure 3). We may assume that this angulation can increase the stress between the proximal neck of the endograft and the ascending aorta.

In regard to endograft design, reports ${ }^{11,12}$ have suggested that a proximal bare stent configuration is associated with an increased risk of RTAD. A recent study ${ }^{3}$ observed no difference in the incidence of RTAD in patients treated with stent-graft with a bare stent versus non-bare stent configuration. In the current study, stent-graft treatment with a proximal bare stent accounted for $46 \%$ of the nonRTAD cases, and 50\% (3 of 6) of the RTAD cases. But this study did have potential sources of error, bias, and confounding.

In our series, the 3 retrograde dissections that occurred after implantation of non-bare stent endografts are not device related. In addition, we observed that an endograft diameter of $>42 \mathrm{~mm}$ might play an important role in the development of retrograde aortic dissection. The diameter of the device is likely not the real issue; rather the dissection may reflect the oversizing and/or the proximal aortic neck diameter. 


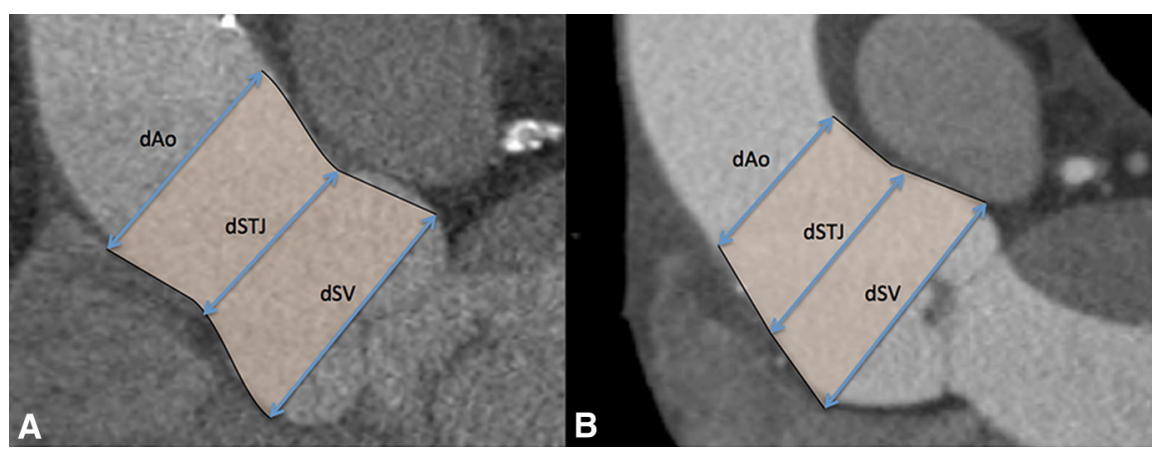

FIGURE 3. A preoperative CT scan shows a comparison of (A) normal root morphology and (B) abnormal root morphology with loss of sinotubular junction. $d A o$, Aorta diameter; $d S T J$, sinotubular junction diameter; $d S V$, sinus of Valsalva diameter.

\section{Aortic-Related RTAD: Aortic Wall Fragility}

Clearly, retrograde dissection is associated with fragility of the aortic wall. The European Registry on Endovascular Aortic Repair Complications, by Eggebrecht and colleagues, ${ }^{12}$ captured 48 TEVAR cases in patients who have Marfan syndrome (RTAD incidence $8.3 \%$ ); and Dong and colleagues ${ }^{13}$ revealed that among 4 patients with Marfan syndrome, 3 developed retrograde dissection after TEVAR. In this study, none of the patients presented with Marfan syndrome, but 2 patients with aortic arch malformation had RTAD. The first patient was treated for a voluminous Kommerell's diverticulum associated with a right-sided aortic arch. In the second case, the patient was treated for a right aberrant subclavian artery. Surgical findings of particular arterial fragility suggested that this malformation might be associated with aortic fragility and thus predispose these patients to retrograde dissection.

\section{Aortic-Related RTAD: Aortic Morphology}

Williams and colleagues ${ }^{14}$ demonstrated for the first time a correlation between ascending aortic diameter and retrograde dissection. In this study, significantly more patients with RTAD had an ascending aortic diameter $\geq 4.0 \mathrm{~cm}$ ( $67 \%$ vs $26 \%$, respectively; $P=.047)$. The current study showed that more patients with RTAD had an ascending aortic diameter $\geq 40 \mathrm{~mm}(15 \%$ vs $33 \%$; $P=.31)$ but the difference was not significant. To better explain why more women have RTAD, ascending aorta diameter was indexed to body surface area, which was a significant risk factor for retrograde dissection $(P=.003)$.

Particular attention was given to evaluating a possible link between aortic root morphology and retrograde aortic dissection. Among the 6 patients who had RTAD, 2 presented preoperatively with a sinus of Valsalva diameter of $\geq 40 \mathrm{~mm}(33 \%$ vs $15 \%, P=.31)$. But more than the diameter itself, global morphology of the aortic root seems to play a key role. Three patients presented with abnormal aortic root morphology as loss of the sinotubular junction (an obliterated sinotubular junction was established when the sinotubular junction diameter was $\geq$ the ascending aorta diameter) and developed retrograde dissection (Figure 3). Abnormal aortic root morphology is likely a marker of diffuse aortic disease and inherent weakness of the diseased aortic wall. Moreover, these 3 patients underwent total root replacement during surgical conversion.

\section{How Can Retrograde Dissection Be Prevented?}

The complication of RTAD is multifactorial, and every favorable factor should be considered to safely perform hybrid aortic arch repair. The first objective is to reduce intraprocedural aortic trauma. Rapid pacing during lateral aortic cross-clamping may be of benefit. In addition, crossing the aortic valve with the stiff wire and pressing it along the left ventricle wall could provide more stability during deployment of the endograft and avoid intimal trauma within the aortic root.

Special attention should be paid to the aortic root, the ascending aorta, and the aortic arch morphology. Ascending aortic replacement before TEVAR ${ }^{15}$ should be considered when the proximal aortic neck diameter is $>40 \mathrm{~mm}$. A dilated root, and more specifically, abnormal root morphology, such as loss of the sinotubular junction, should function as a warning to practitioners, which requires, on their part, becoming skilled in the use of radiologic software. Such knowledge may limit the risk of misestimating aortic diameter, and increase precision in the choice of the most appropriate endograft with limited oversizing. Finally, the role of $\mathrm{TEE}^{16}$ remains unproven, but in our series, 3 retrograde dissections that likely occurred during the procedure would probably have been detected earlier if TEE was used systematically. The chief limitation of our study is the relatively small number of patients, which affects the power of the study.

\section{CONCLUSIONS}

These data indicate that retrograde ascending dissection is a serious and common complication of an expanding hybrid strategy for treating pathology of the aortic arch. 
Detailed screening of the aortic arch, the ascending aorta, and aortic root morphology is critical. In the presence of predisposing factors, combined ascending aorta replacement should be considered.

\section{Conflict of Interest Statement}

Authors have nothing to disclose with regard to commercial support.

\section{References}

1. Vallabhajosyula P, Szeto W, Desai N, Bavaria JE. Type I and type II hybrid aortic arch replacement: postoperative and mid-term outcome analysis. Ann Cardiothorac Surg. 2013;2:280-7.

2. Canaud L, Hireche K, Berthet JP, Branchereau P, Marty-Ané C, Alric P. Endovascular repair of aortic arch lesions in high-risk patients or after previous aortic surgery: midterm results. J Thorac Cardiovasc Surg. 2010;140:52-8.

3. Canaud L, Ozdemir BA, Patterson BO, Holt PJ, Loftus IM, Thompson MM. Retrograde aortic dissection after thoracic endovascular aortic repair. Ann Surg. 2014;260:3889-95.

4. Totaro M, Miraldi F, Fanelli F, Mazzesi G. Emergency surgery for retrograde extension of type B dissection after endovascular stent graft repair. Eur $J$ Cardiothorac Surg. 2001;20:1057-8.

5. Neuhauser B, Czermak BV, Fish J, Perkmann R, Jaschke W, Chemelli A, et al. Type A dissection following endovascular thoracic aortic stent-graft repair. J Endovasc Ther. 2005; 12:74-81.

6. Ishimaru S. Endografting of the aortic arch. J Endovasc Ther. 2004;11(Suppl 2): II62-71.

7. Canaud L, Joyeux F, Ziza V, Branchereau P, Marty-Ané C, Alric P. Hemi-aortic arch debranching for hybrid aortic arch repair by sequential transposition of the left common carotid and subclavian arteries. J Thorac Cardiovasc Surg. 2013; $145: 764-7$.
8. Patterson B, Holt P, Nienaber C, Cambria R, Fairman R, Thompson M. Aortic pathology determines midterm outcome after endovascular repair of the thoracic aorta: report from the Medtronic Thoracic Endovascular Registry (MOTHER) database. Circulation. 2013;127:24-32.

9. Van Prehn J, Vincken KL, Muhs BE, Barwegen GK, Bartels LW, Prokop M, et al. Toward endografting of the ascending aorta: insight into dynamics using dynamic cine-CTA. J Endovasc Ther. 2007;14:551-60.

10. Kpodonu J, Preventza O, Ramaiah VG, Shennib H, Wheatley GH III, Rodriquez-Lopez J, et al. Retrograde type A dissection after endovascular stenting of the descending thoracic aorta. Is the risk real? Eur J Cardiothorac Surg. 2008;33:1014-8.

11. Neuhauser B, Greiner A, Jaschke W, Chemelli A, Fraedrich G. Serious complications following endovascular thoracic aortic stent-graft repair for type B dissection. Eur J Cardiothorac Surg. 2008;33:58-63.

12. Eggebrecht H, Thompson M, Rousseau H, Czerny M, Lönn L, Mehta RH, et al. Retrograde ascending aortic dissection during or after thoracic aortic stent graft placement: insight from the European registry on endovascular aortic repair complications. Circulation. 2009;120(11 Suppl):S276-81.

13. Dong $\mathrm{ZH}$, Fu WG, Wang YQ, Guo da Q, Xu X, Ji Y, et al. Retrograde type A aortic dissection after endovascular stent graft placement for treatment of type B dissection. Circulation. 2009;119:735-41.

14. Williams JB, Andersen ND, Bhattacharya SD, Scheer E, Piccini JP, McCann RL, et al. Retrograde ascending aortic dissection as an early complication of thoracic endovascular aortic repair. J Vasc Surg. 2012;55:1255-62.

15. Kent WD, Appoo JJ, Bavaria JE, Herget EJ, Moeller P, Pochettino A, et al. Results of type II hybrid arch repair with zone 0 stent graft deployment for complex aortic arch pathology. J Thorac Cardiovasc Surg. 2014;148: 2951-5.

16. Kpodonu J, Ramaiah VG, Diethrich EB. Intravascular ultrasound imaging as applied to the aorta: a new tool for the cardiovascular surgeon. Ann Thorac Surg. 2008;86:1391-8.

Key Words: aneurysm, aorta, aortic arch, stent-graft, retrograde type A dissection

\title{
EDITORIAL COMMENTARY
}

\section{Nothing comes for free}

\author{
Anthony L. Estrera, MD
}

See related article on pages 136-42.

\footnotetext{
From the Department of Cardiothoracic and Vascular Surgery, The University of Texas Medical School at Houston, Memorial Hermann Heart \& Vascular Institute, Houston, Tex.

Disclosures: Author has nothing to disclose with regard to commercial support. Received for publication April 17, 2015; accepted for publication April 17, 2015. Address for reprints: Anthony L. Estrera, MD, Department of Cardiothoracic and Vascular Surgery, The University of Texas Medical School at Houston, 6400 Fannin St, Suite 2850, Houston, TX 77030 (E-mail: Anthony.L.Estrera@uth.tmc.edu). J Thorac Cardiovasc Surg 2015;150:142-4 $0022-5223 / \$ 36.00$

Copyright $(\odot) 2015$ by The American Association for Thoracic Surgery http://dx.doi.org/10.1016/j.jtevs.2015.04.041
}

In 2005, the US Food and Drug Administration (FDA) approved the first device for the endovascular treatment of aneurysms of the descending thoracic aorta. ${ }^{1}$ Since that time, improvements in technique and advancements in device design have led to improved outcomes with thoracic endovascular aortic repair (TEVAR). During the past decade, TE-

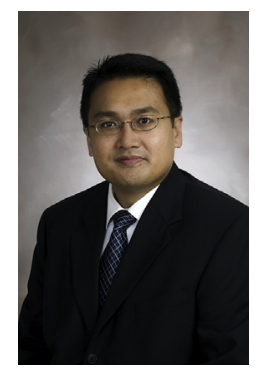
VAR has been applied for nearly all types of aortic pathology, becoming the prevailing therapeutic intervention in conditions such as traumatic transection, symptomatic penetrating ulcers, and acute complicated type B aortic dissection. Controversy, 